\title{
Feedback on Foundation Course Curriculum from the New Indian Medical Graduates
}

\author{
Udgiri, R. \& Patil, V.
}

\begin{abstract}
Introduction: Foundation course is one of the new curricula Medical council of India implemented for the present academic course at the beginning of the MBBS program It is a month duration where all the students should undergo this foundation course. In this course, students were sensitized to a new professional environment which is going to help them in their career as a medical profession. The purpose of the course is to orient the students in all aspects of the medical college environment, equipping them with certain basic skills required for patient care, enhancing their communication, language and computer and learning skills. Sports and extracurricular activities are also given importance in the foundation course. The present study was an attempt to take responses in the form of feedback by the students with regards to the foundation course.
\end{abstract}

Methods: It was a cross-sectional study. Institutional ethical clearance was taken before the start of the study. After taking consent from the students, the data was collected using self-administered, semistructured questionnaires. The feedback form with the foundation course was e-mailed to all the newly joined first year students of Bijapur Lingayat District Educational (Deemed to be University) Shri.B.M.Patil Medical College hospital \& Research Centre. Karanataka, India.

Results: The majority of students said implementation of the foundation course for Indian medical graduate was good, but the duration of the course was lengthy.

Conclusion: The study makes it evident that the foundation course introduced at the commencement of the MBBS programme is important for medical undergraduates to acquire basic skills in the medical profession.

Key words: Foundation course, Indian medical graduates, Medical Council of India

\section{Introduction}

Foundation course is one of the new curricula Medical council of India $\mathrm{MCl}$ has implemented for the present academic course at the beginning of the MBBS course. In this course, students were sensitized to a new professional environment which is going to help them in their career as a medical profession.

Shri. B.M. Patil Medical College, Vijayapura, Karnataka.

Corresponding Author: Dr.Rekha Udgiri

Plot No 38, OM,

Sadashiva Nagar,

Ashram Road,

Vijayapura- 586103, India.

Email:drrekhaudgiri@gmail.com
The purpose of this course is to orient the students in all aspects of the medical college environment, equipping them with the certain basic skill required for patient care, enhancing their communication, language and computer and learning skills (MCl 2019). No study has been published about literature in general after implementation of the foundation course by the Medical Council of India.

The present study was an attempt to take responses in the form of feedback by the students with regards to a foundation course, with the aim to evaluate the perception of the students regarding the importance of the foundation course in the medical program. 


\section{Objectives}

1. To assess the responses with regards to the foundation course by the students.

2. Based on the analysis of feedback, a recommendation should be made for undergraduate medical curriculum.

\section{Methods}

The total duration of the study was six months, study participants were the newly joined first year students of BLDE (Deemed to be University) Shri. B. M. Patil Medical College. After taking ethical clearance from the institutional ethical committee and informed consent from the participants the study was carried out. A self- administered, semistructured questionnaire was used to collect the data and the validity of the question was pretested. After completing the foundation course of one- month duration according to $\mathrm{MCl}$ protocol, this study was carried out through email, questionnaires (feedback format) along with the foundation course curriculum was sent to study participants. A LIKERT scale was applied for the structured components related to a foundation course curriculum. The purpose of the study was explained to them and briefed all the questions before sending the feedback form. The total sample size constitutes 124 . Statistical analysis was done using SPSS version 20.

\section{Results}

A total of 124 students participated in the feedback; the majority of the participants labeled the foundation program was a good initiative made by $\mathrm{MCl}$ and. none of them said it was very poor. More than $59 \%$ of the respondents said the goals and objective of the foundation course was good, and $17 \%$ said it was very good .None of them said it was poor. With regard to course content and organization, $29 \%$ said content was well planned with theory and practical classes, well-structured to achieve learning outcomes, and teaching learning methods adopted were appropriate. $50 \%$ said the depth of assessment of syllabus and teaching-learning methods adopted were good. Maximum number (48\%) of respondents said course content was able to meet the health care needs and the problem of the community The other questionnaires were asked to students viz career -oriented, a load of the syllabus, skill lab facilities .More than $40 \%$ of them gave their response related to foundation course was good with related to course like-it is was career oriented, size of the syllabus in term of load on the students, interested generated by the teacher regarding syllabus. More than $50 \%$ of them said the quality of teaching and treatment of the students by faculty was good. $48 \%$ of them had rated that skill lab facilities were good. In open-ended responses, the majority of them were in the opinion that duration of the course should be between 1520 days. Especially sessions dealing with acquiring skills like Basic life support, first aid, biomedical waste management and Universal precautions topics are very informative and helpful. But some of the topics like constitution, yoga, career-oriented and writing logbooks were not relevant to the course. An introduction to the actual academic course would be better along with the course. Suggested to involve more interactive teaching-learning session in which students will be kept active .Language classes should be conducted daily. The majority of them preferred more practical classes instead of theory class. Sports hours should be increased. They opine that video demonstration sessions were interesting and also there were some repetitions of the topics. Extracurricular activities were well organized and planned.

They suggested a small research project should have been given as an activity for off class hours during the foundation course. They also suggested that the course should have been started after completing all admissions.

\section{Discussion}

Implementation of the foundation course in MBBS was aimed at creating medical students to serve as health care providers who need not only provide adequate, appropriate and costeffective health care service but also need to be the leaders of their community. The Foundation Course will also provide a sound foundation for learning in the MBBS course and later in their professional career. ( $\mathrm{MCl} 2019$ ) There is no available literature in general after the implementation of a foundation course by $\mathrm{MCl}$.

In the present study, the majority of the participants labeled the foundation program was a good initiative taken up by the $\mathrm{MCl}$. None of them said it was very poor. A similar study was done by Mittal et al. observed that $67 \%$ of the participants said, the foundation program was a very good exercise and none of the students felt it was poor (Mittal 2013). In another study done by Dr. Rohit Dixit et al observed that the overall rating for the foundation course was $4.19 \pm 0.61$. (Dixit 2019)This shows that the 
foundation course was helpful to everyone and it is a need for the day.

In our study, the majority of respondents preferred more practical classes instead of theory class. The same opinion was observed in the study conducted by Priyadarshini et al. responses like making the sessions more interactive and including role-plays. (Mishra, 2017) This reflects the need to modify some of the topic as small group teaching instead of didactic methods.

The present study observed that Basic life support, first aid, biomedical waste management and Universal precautions topics are very informative and helpful. A similar study conducted by Singh et al. and Srimathi observed the positive response of the student related to skill- based learning (Singh, 2007; Srimathi, 2014) shows that the students are more enthusiastic to learn skill- based learning.

Findings of the present study suggest that students need more language classes and the course should start after completing all admissions. This could be due to the reason that our college is an autonomous medical college where the majority of the students get admitted from different states and have a problem with the local language .and till the last round of national eligibility entrance test (NEET) counseling; the students get admitted to medical college. Therefore students suggested starting the course after completion of all admissions.

Table 1: Students Responses Related to Foundation Course

\begin{tabular}{|c|c|c|c|c|c|c|}
\hline Components & Very good & Good & Average & Poor & $\begin{array}{l}\text { Very } \\
\text { poor }\end{array}$ & Total \\
\hline \multicolumn{7}{|c|}{ Students response to goals $\&$ objectives } \\
\hline $\begin{array}{l}\text { Course gives a Clear } \\
\text { idea about what is } \\
\text { expected outcome from } \\
\text { this course }\end{array}$ & $21(16.9 \%)$ & $73(58.9 \%)$ & $27(21.85)$ & $3(2.4 \%)$ & - & 124 \\
\hline $\begin{array}{l}\text { How do you rate the } \\
\text { course objectives stated } \\
\text { are well aligned with the } \\
\text { course content? }\end{array}$ & $19(15.3 \%)$ & $72(58.1 \%)$ & $26(21 \%$ & $7(5.6 \%)$ & - & 124 \\
\hline \multicolumn{7}{|c|}{ Responses related to course content \& organization } \\
\hline $\begin{array}{l}\text { Is the course identify the } \\
\text { healthcare needs and } \\
\text { problem of the } \\
\text { community? }\end{array}$ & $40(32.3 \%)$ & $60(48.4 \%)$ & $23(18.5 \%)$ & $01(0.8 \%)$ & - & 124 \\
\hline $\begin{array}{l}\text { Is the course has Well } \\
\text { planned theory and } \\
\text { practical hours/classes? }\end{array}$ & $18(14.5 \%)$ & $59(4.6 \%)$ & $36(29 \%)$ & $11(8.8 \%)$ & & 124 \\
\hline $\begin{array}{l}\text { Course content is well } \\
\text { structured to achieve } \\
\text { the leaning outcome }\end{array}$ & $18((14.5 \%)$ & $59(4.6 \%)$ & $36(29 \%)$ & $11(8.8 \%)$ & & 124 \\
\hline \multicolumn{7}{|c|}{ Responses related to $T / L$ method \& assessment methods } \\
\hline $\begin{array}{l}\text { Teaching-learning } \\
\text { methods adopted were } \\
\text { appropriate }\end{array}$ & $17(13.7 \%)$ & $62(50 \%)$ & $36(29 \%)$ & $9(7.2 \%)$ & - & 124 \\
\hline $\begin{array}{l}\text { How do you rate depth } \\
\text { of assessment of } \\
\text { syllabus content? }\end{array}$ & $16(12.9 \%)$ & $63(50.8 \%)$ & $35(28.2 \%)$ & $10(8.06 \%)$ & - & 124 \\
\hline
\end{tabular}




\section{Conclusion}

The present study concludes that the majority of the students felt that the topics covered during the course are essential for the medical profession except for yoga, constitution, and various career pathways models. Foundation course has helped the students coming from a different learning environment to cope with the vast body of knowledge and skills required in the dynamic and rapidly changing healthcare system. The foundation course has enabled the MBBS program to be restructured, making students more participatory and competent. We recommend that such programs should be conducted regularly in all the medical colleges with feedback analysis.

\section{Conflict of Interest}

The authors declare no conflict of interest.

\section{References}

Dixit R., Joshi K.P., Suhasini P. \& Jamadar D. (2019) Students' Perception of Foundation Course - A New Experience in MBBS Curriculum in India. International Journal of Medical Science and Education 6, 3, pp. 1-7.
Medical Council of India (2019) Foundation course for the undergraduate medical program. Available at: Medical Council of India. Foundation Course for the Undergraduate Medical Education Program, 2019: pp. 1-46. [Accessed on: 1 August 2019].

Mittal, R., Mahajan, R. \& Mittal, N. (2013) Foundation programme: A Student's Perspective. International Journal of Applied and Basic Medical Research, 3, 1, pp. 52.

Mishra, P. \& Kar, M. (2017) Perception of Students on Foundation Course Conducted for First Year MBBS Students at AlIMS Bhubaneswar. Community \& Family Medicine, 3, 2.

Singh, S., Ghosh, S. \& Pandya, H. (2007) Foundation Programme for MBBS Students at Entry Level: Experience at an Indian Medical School. South East Asian Journal of Medical Education, 1, pp. 33-37.

Srimathi, T. (2014) A study on Students Feedback on the Foundation Course in First Year MBBS Curriculum. International Journal of Medical Research \& Health Sciences, 3, 3, pp. 575-579. 